\title{
Potentiostatic Study on the Anodic Behaviour of Iron-Nickel Alloys*
}

\author{
By Kunio Shiobara**, Yoshinobu Sawada** \\ and Susumu Morioka**
}

\begin{abstract}
The anodic behaviour of annealed iron-nickel alloys containing 0 to $100 \% \mathrm{Ni}$ in deaerated $1 \mathrm{M} / \mathrm{L}$ sulphuric acid solutions was studied. A semi-conductor type potentiostat was used for polarization measurements. The results obtained were compared with those for iron-chromium alloys as follows: (1) A negative loop observed in iron-chromium alloys was not shown in the anodic polarization curves of any of the iron-nickel alloys studied. (2) The anodic current densities at the passive state of the iron-nickel alloys were far greater than those of the iron-chromium alloys, but smaller than those of the latter in the trans-passive region. (3) A different Flade potential was obtained for a different setting potential for the alloys containing more than $30 \% \mathrm{Ni}$. This phenomenon was not observed in the iron-chromium alloys.
\end{abstract}

(Received September 21, 1964)

\section{Introduction}

The anodic behaviour of pure iron and nickel has been studied by many investigators, but few studies $^{(1)(2)}$ are available on the anodic behaviour of iron-nickel alloys.

In a previous investigation ${ }^{(3)}$ the anodic behaviour of iron-chromium alloys in sulphuric acid solutions was studied using a potentiostat. The purpose of the present investigation was to examine potentiostatically in detail the anodic behaviour of iron-nickel alloys containing 0 to $100 \%$ nickel, particularly in connection with the effect of nickel content on the anodic behaviour which has not been successfully detected by a applied voltagestep method ${ }^{(1)}$. In addition, the Flade potentials of the iron-nickel alloys were also examined in detail.

\section{Apparatus and Procedure}

The chemical compositions of 11 alloys used are shown in Table 1. The specimens were vacuum-annealed at $900^{\circ} \mathrm{C}$ for $15 \mathrm{~min}$, and then furnace-cooled to room temperature. The potentiostat used was of the semi-conductor type. All the experiments were carried out in $1 \mathrm{M} / \mathrm{L}$ sulphuric acid solutions at $25^{\circ} \mathrm{C}$. The electrical apparatus and circuit were the same as those used elsewhere ${ }^{(3)}$. The dissolved oxygen was removed by passing high purity nitrogen gas through the electrolyte untill it was reduced to less than $10^{-6} \mathrm{M} / \mathrm{L}^{(3)}$.

For obtaining the polarization curves in the active state, the anode potential was raised in steps of $0.02 \mathrm{~V}$, keeping each potential constant for $1 \mathrm{~min}$. After the specimens became passive, the potential was raised in steps of $0.05 \mathrm{~V}$, maintaining each potential constant for $2 \mathrm{~min}$. The potentlial of the specimen was measured in comparison with the saturated calomel electrode potential.

\section{Results and Discussion}

\section{Anodic polarization measurement}

Table 1 Chemical compositions of specimens.

\begin{tabular}{|c|c|c|c|c|c|c|c|c|c|}
\hline Alloys & C & $\mathrm{Si}$ & $\mathrm{Mn}$ & $\mathbf{P}$ & $\mathrm{S}$ & $\mathbf{C r}$ & $\mathrm{Ni}$ & $\mathrm{Fe}$ & $\mathbf{N}$ \\
\hline $\begin{array}{c}\mathrm{Fe} \\
10 \% \mathrm{Ni}-\mathrm{Fe} \\
20 \% \mathrm{Ni}-\mathrm{Fe} \\
30 \% \mathrm{Ni}-\mathrm{Fe} \\
40 \% \mathrm{Ni}-\mathrm{Fe} \\
50 \% \mathrm{Ni}-\mathrm{Fe} \\
60 \% \mathrm{Ni}-\mathrm{Fe} \\
70 \% \mathrm{Ni}-\mathrm{Fe} \\
80 \% \mathrm{Ni}-\mathrm{Fe} \\
90 \% \mathrm{Ni}-\mathrm{Fe} \\
\mathrm{Ni}\end{array}$ & $\begin{array}{l}0.011 \\
0.005 \\
0.005 \\
0.006 \\
0.006 \\
0.005 \\
0.005 \\
0.006 \\
0.005 \\
0.005 \\
0.005\end{array}$ & $\begin{array}{l}0.52 \\
0.31 \\
0.38 \\
0.35 \\
0.31 \\
0.27 \\
0.42 \\
0.42 \\
0.44 \\
0.46 \\
0.40\end{array}$ & $\begin{array}{l}0.48 \\
0.46 \\
0.46 \\
0.44 \\
0.46 \\
0.42 \\
0.44 \\
0.46 \\
0.44 \\
0.47 \\
0.44\end{array}$ & $\begin{array}{l}0.011 \\
0.005 \\
0.006 \\
0.005 \\
0.006 \\
0.005 \\
0.005 \\
0.004 \\
0.002 \\
0.004 \\
0.002\end{array}$ & $\begin{array}{l}0.016 \\
0.009 \\
0.007 \\
0.007 \\
0.009 \\
0.007 \\
0.006 \\
0.005 \\
0.005 \\
0.006 \\
0.005\end{array}$ & $\begin{array}{l}0.16 \\
- \\
- \\
- \\
\operatorname{tr} \\
\operatorname{tr} \\
\operatorname{tr} \\
\operatorname{tr} \\
\operatorname{tr}\end{array}$ & $\begin{array}{r}0.01 \\
10.17 \\
19.95 \\
29.68 \\
39.49 \\
48.85 \\
\text { Bal } \\
\text { Bal } \\
\text { Bal } \\
\text { Bal } \\
\text { Bal }\end{array}$ & $\begin{array}{r}\mathrm{Bal} \\
\mathrm{Bal} \\
\mathrm{Bal} \\
\mathrm{Bal} \\
\mathrm{Bal} \\
\mathrm{Bal} \\
39.03 \\
28.98 \\
19.22 \\
9.00 \\
0.17\end{array}$ & $\begin{array}{l}0.004 \\
= \\
= \\
= \\
= \\
= \\
=\end{array}$ \\
\hline
\end{tabular}

* This paper was published in Japanese in The Journal of the Japan Institute of Metals, 28 (1964), 1.

** Department of Metallurgy, Faculty of Engineering, Tohoku University, Sendai, Japan.

(1) S. Morioka and K.Sakiyama : J. Japan. Inst. Metals, 19(1955), 31.

(2) G. Economy, R. Speiser, F. H. Beck and M. G. Fontana : J. Electrochem. Soc., 108 (1961), 337.

(3) K.Shiobara, Y.Sawada and S.Morioka : Trans. JIM, 6(1965), 58.
The anodic polarization curves for 11 iron-nickel alloys are shown in Fig. 1. As reported in a previous paper (3), pure iron (curve 1) displays a dissolution current maximum at $-0.2 \mathrm{~V}$ followed by a second maximum at about $+0.3 \mathrm{~V}$ where an oscillation of the current is observed.

In contrast with the behaviour of iron-chromium alloys, the corrosion potential and the first dissolution current maximum of iron-nickel alloys move to the noble 
direction as the nickel content is increased. The second dissolution current maximum, however, moves to the negative direction with increase of the nickel content and disappeares at about $40 \% \mathrm{Ni}$.

In the case of iron-chromium alloys, a negative loop

\section{(1) Corrosion potential}

The variation of the corrosion potential with the nickel content is shown in curve (A) in Fig. 2. The corrosion potential rises with the nickel content in the

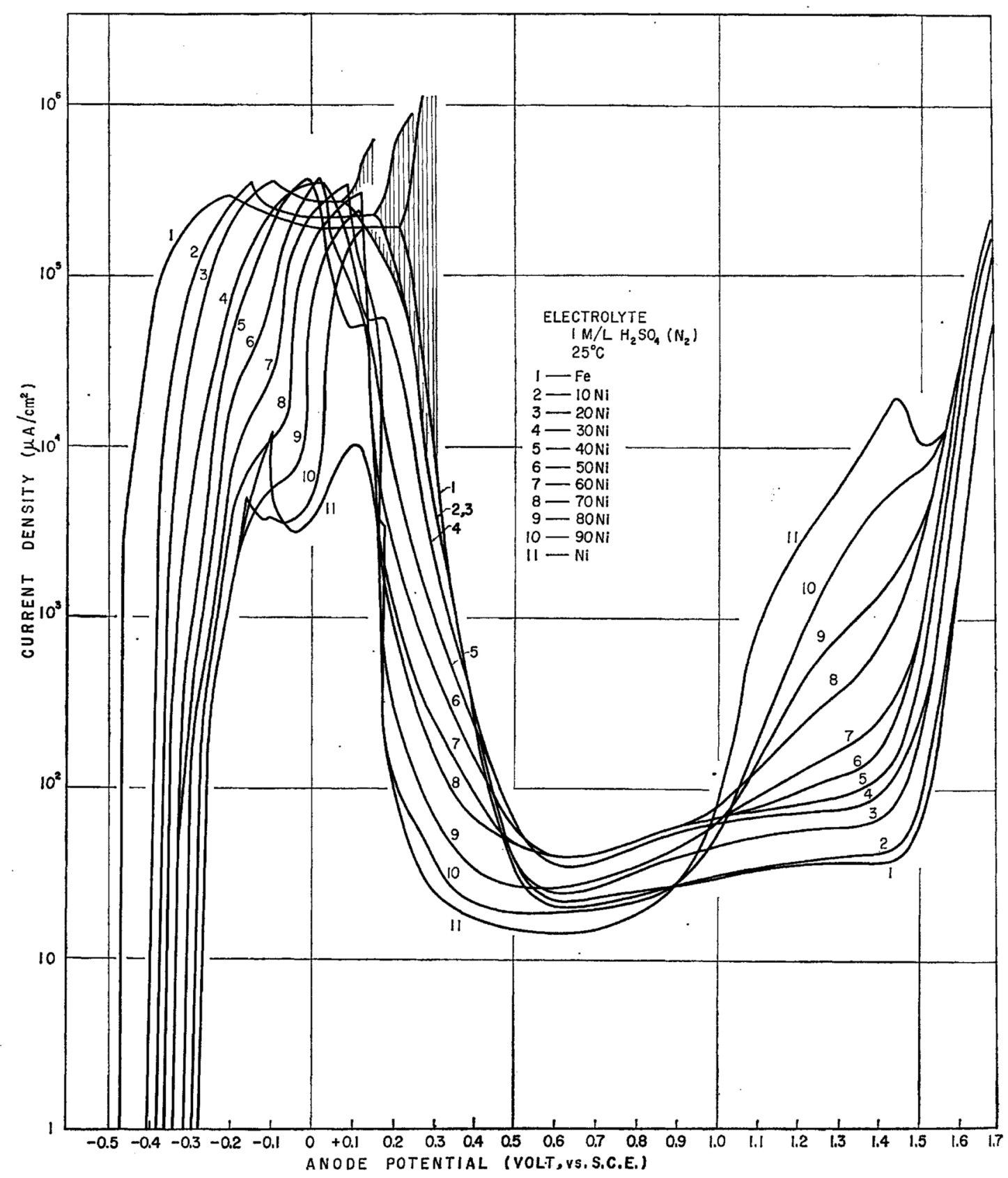

Fig. 1 Potentiostatic polarization curves for iron-nickel alloys in $1 \mathrm{M} / \mathrm{L} \mathrm{H}_{2} \mathrm{SO}_{4}$ at $25^{\circ} \mathrm{C}$.

was observed in the polarization curves for the alloys with more than $22 \% \mathrm{Cr}$ in the potential region between ca. -0.4 and $0 \mathrm{~V}$ (vs. S.C.E.), but in the case of ironnickel alloys, no negative loop was observed for all of the specimens studied; this is because all of the specimens were in the active state in the above potential region and the anodic dissolution current was much higher than the reducing current of hydrogen ions in the active potential region.

The trans-passive state appears at about $1.1 \mathrm{~V}$. The anodic current in this state increases with increase of the nickel content, but it is still much lower than that of iron-chromium alloys in the trans-passive state. region of the $\alpha$ phase region and slightly in the $\gamma$ phase region. The result is in good agreement with that of Economy and his coworkers ${ }^{(2)}$. Since the corrosion potential is established by the anodic dissolution reaction of alloys and the cathodic reduction of hydrogen ions, if the hydrogen evolution reaction is not affected by alloying nickel, two major causes can be considered to explain the increase in corrosion potential with the nickel content; the increase of the nickel content shifts the single electrode potential of $\mathrm{Fe}$ in the alloys, and increases the polarization resistance of anodic dissolution.

\section{(2) Passivation potential}


The variation of the potentials at two dissolution current maxima with the composition are shown in curves (B) and $(\mathrm{C})$ in Fig. 2. The potentials at the first current maximum (curve $(B)$ ) increase and the potentials at the second current maximum (curve $(\mathrm{C})$ ) decrease with the

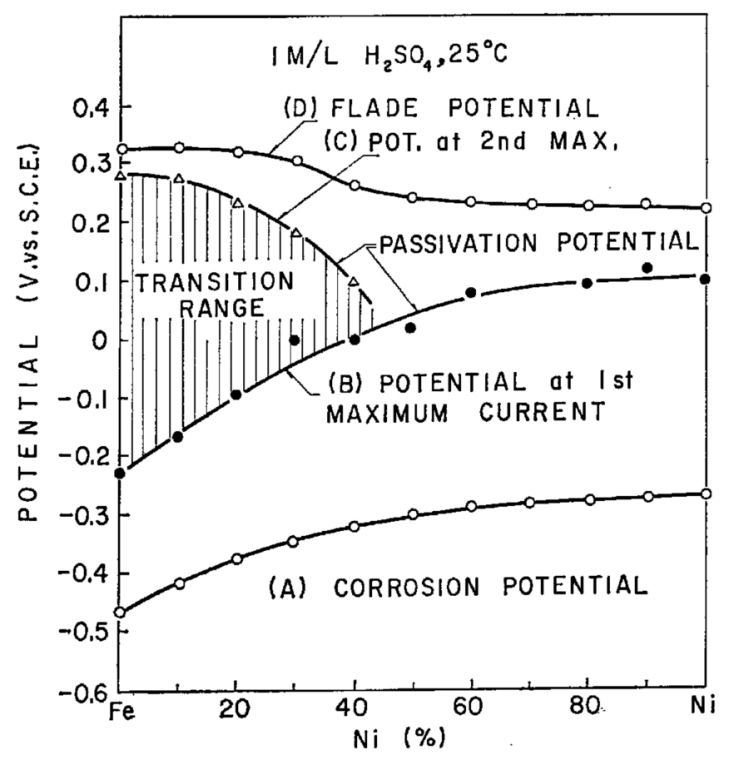

Fig. 2 Effect of the nickel content in the alloy on the corrosion potential, passivation potential and Flade potential.

nickel content. Correspondingly, the potential-range for transition from the active to the passive state becomes narrower with the nickel content and vanishes at about $40 \% \mathrm{Ni}$. The passivation potential which is defined as the potential corresponding to the maximum dissolution current just before the passivation varies along with curve $(\mathrm{C})$ and coincides with curve $(\mathrm{B})$ at about $40 \% \mathrm{Ni}$.

(3) Passivation current (Maximum current density in the active state)

The variation of the passivation current with the composition is shown in Fig. 3 . The passivation current decreases with the nickel content, but the effect of nickel is not so remarkable as that of chromium.

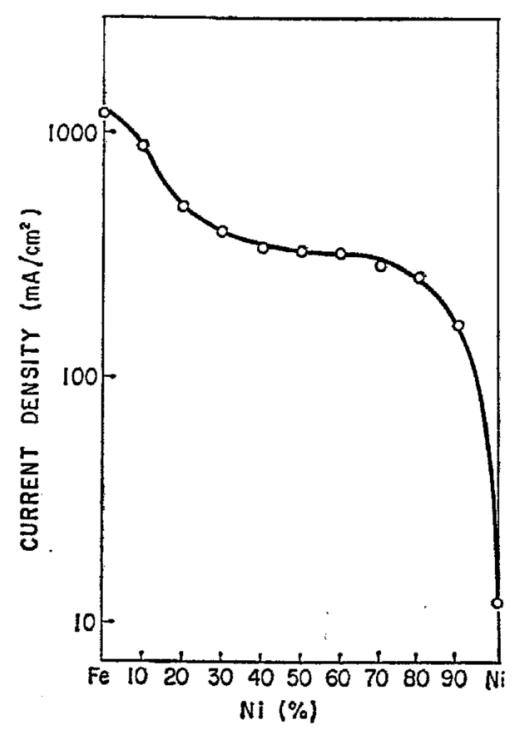

Fig. 3 Effect of the nickel content in the alloy on the passivation current density.

\section{(4) Current in the passive state}

The anodic current density at a potential of $+0.6 \mathrm{~V}$ is plotted in Fig. 4 (curve (A)). It is seen that the passivity of pure iron and nickel is more stable than that

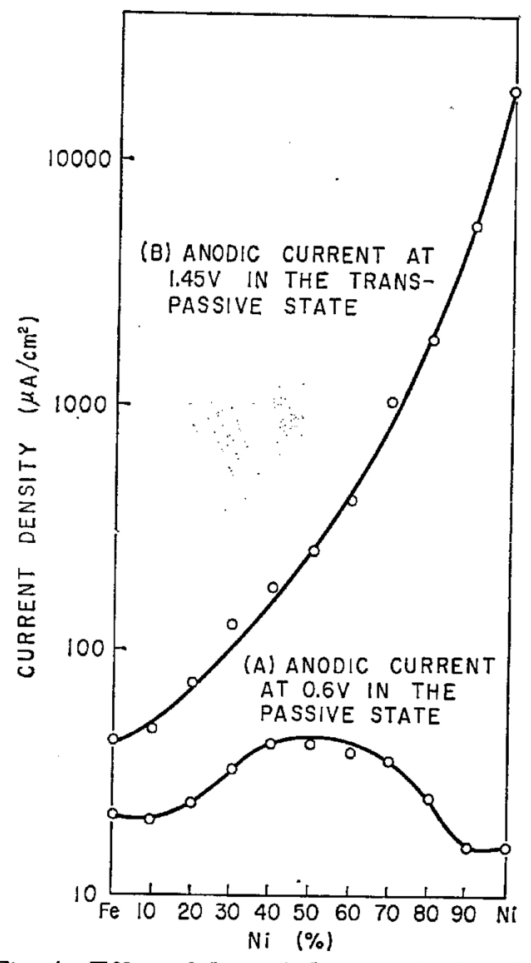

Fig. 4 Effect of the nickel content in the alloy on the anodic current density in passive state and trans-passive state.

of iron-nickel alloys, i.e., the current densities in the passive state for $30 \sim 70 \% \mathrm{Ni}-\mathrm{Fe}$ alloys are $20 \sim 45 \mu \mathrm{A}$ / $\mathrm{cm}^{2}$ which is higher than those of pure iron and nickel, and they are more than ten times as large as those of iron-chromium alloys with more than $12 \% \mathrm{Cr}$.

\section{(5) Current in the trans-passive state}

The anodic current density at a potential of $1.45 \mathrm{~V}$ is plotted in Fig. 4 (curve (B)). A steep increase of the current density with the nickel content was observed to be $10^{2} \mu \mathrm{A} / \mathrm{cm}^{2}$ for $30 \% \mathrm{Ni}$, and $10^{3} \mu \mathrm{A} / \mathrm{cm}^{2}$ for $70 \%$ $\mathrm{Ni}$. These values are much lower than $10^{5} \mu \mathrm{A} / \mathrm{cm}^{2}$ for $30 \% \mathrm{Cr}$, so that the dissolution current densities in the trans-passive state of iron-nickel alloys are known to be much lower than those of iron-chromium alloys.

\section{Flade potential}

In order to obtain the Flade potential, the electrode potential was set at $1.4 \mathrm{~V}$ to measure the potential decay. The Flade potential vs. nickel content curve is different from the passivation potential vs. nickel content relationship. A further examination on the cause of this difference showed that the Flade potential was affected by the setting potential. The relationship between the Flade potential and the setting potential is shown in Fig. 5. Broken lines in the figure are the decay time, i.e. the time required for self-activation from the setting potential. 
The figure also shows that for alloys with less than $20 \% \mathrm{Ni}$, the Flade potentials independent of the setting potential take place, but for the alloys with more than $30 \% \mathrm{Ni}$, the higher Flade potentials are obtained for the higher setting potentials; for example, the Flade

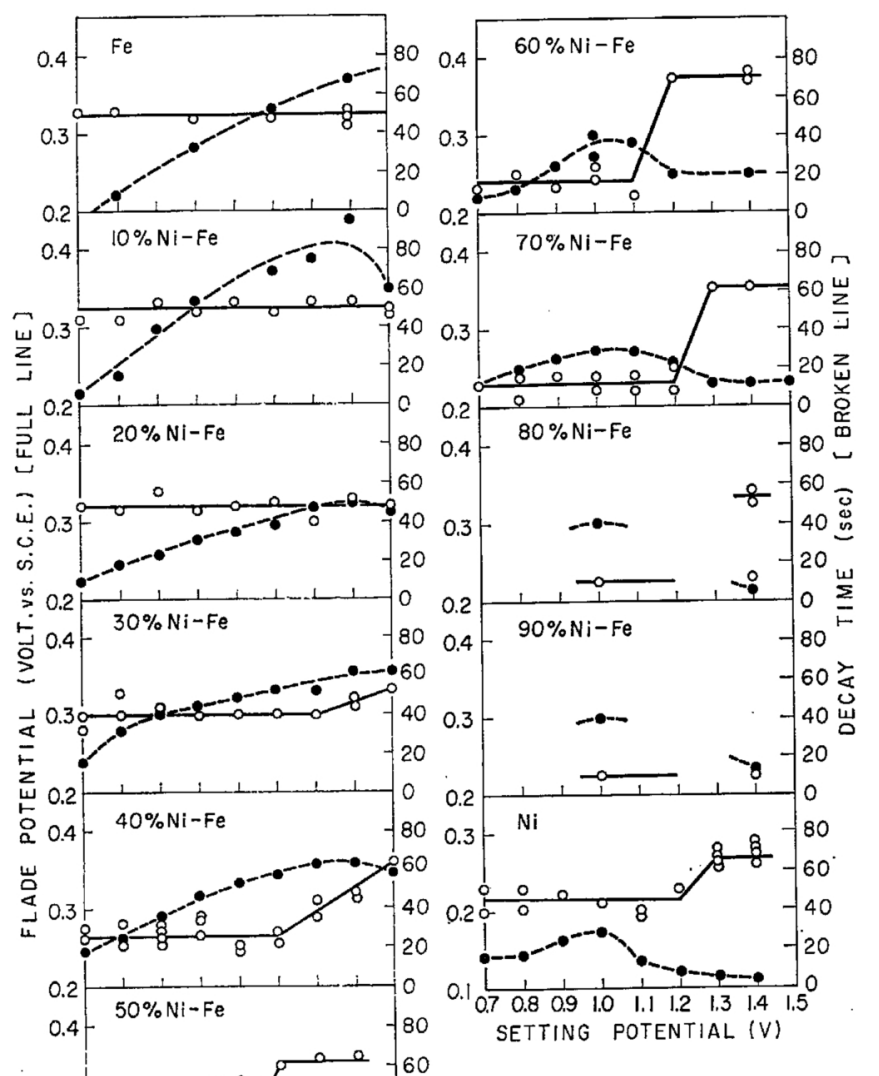

passive region, however, an entirely different tendency was observed in the Flade potential vs. composition relationship (Fig 6, curve (B)). For the setting potentials lower than 1.1 V, the Flade potentials of pure iron and nickel obtained are in good agreement with the values already reported ${ }^{(4)(5)}$ and the observed relationship between the Flade potential and the composition is similar to that of Economy ${ }^{(2)}$.

It is found that a different Flade potential is obtained for a different setting potential. It may be concluded that the Flade potential is not always the boundary potential between the active and passive states but shows the potential at which the passive film formed on metal under the various setting potentials dissolves into the electrolyte. It is considered that the Flade potential of iron is independent of the setting potential because of the lack of trans-passivity, whereas that of iron-nickel alloy deponds upon the setting potential since the structure and properties of the trans-passive film are different from those of the stable passive film.

In the case of iron-chromium alloys having a similar trans-passive phenomenon, the dependence of the Flade potentials on the setting potential was not observed $^{(3)}$. The different behaviour might be attributed to the stability and rapid formation of the passive films of the iron-chromium alloys; the stable passive films would be formed during the potential decay corresponding to the lower potentials. The difference in the stability of the passive films between the ironchromium alloys and iron-nickel alloys was also admitted in the potential decay rate : A small anodic current was needed to retard the rapid decay rate for iron-nickel alloys with more than $70 \% \mathrm{Ni}$, whereas a small cathodic current was required to accelerate the sluggish reactions for the iron-chromium alloys with more than $22 \% \mathrm{Cr}$. As stated above, it is found that the electrochcmical behaviour of iron-nickel alloys is greatly different from those of iron-chromium alloys in respect of the passive current density, the Flade potential, the corrosion potential, etc. setting potential of $1.4 \mathrm{~V}$ and ca. $0.25 \mathrm{~V}$ for $1.1 \mathrm{~V}$, the observed difference being ca. $0.1 \mathrm{~V}$.

The relationship between the Flade potential and the nickel content is shown in Fig. 6. The Flade potentials obtained for the setting potential in the stable passive state lower than $1.1 \mathrm{~V}$ display a tendency similar to the passivation potentials (Fig 6, curve (A) and Fig 2, curve (D)). For the setting potentials of $1.4 \mathrm{~V}$ in the trans-

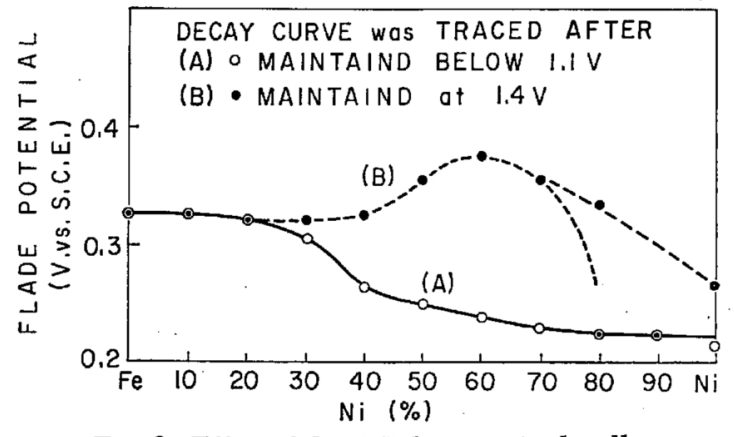

Fig. 6 Effect of the nickel content in the alloy on the Flade potential.

\section{Summary}

The anodic behaviour of annealed iron-nickel alloys containing 0 to $100 \%$ nickel was investigated in deaerated sulphuric acid solutions at $25^{\circ} \mathrm{C}$ by means of an electrochemical technique. A semi-conductor type potentiostat was used for the polarization measurement. The relationships between the nickel content and various properties such as corrosion potential, passivation potential, Flade potential, passivation current density and anodic current densities at the passive and the transpassive states were investigated. It was found that the anodic behaviour of iron-nickel alloys was considerably different from those of iron-chromium alloys ${ }^{(3)}$, as follows :

(1) In contrast with iron-chromium alloys, no negative loop is observed in the anodic polarization curves of any

(4) U. F. Franck ; Z. Naturforsch., 4 a(1949), 378.

(5) G. Okamoto and N. Sato: J. Jopan Inst. Metals, 23(1959), 662 
of the iron-nickel alloys studied.

(2) The anodic current density at the passive state of the iron-nickel alloys is far greater than that of the iron-chromium alloys, but in the trans-passive region, the anodic current density is low for the former compared with those for the latter.
(3) The Flade potential for alloys containing more than $30 \%$ nickel appears to change depending upon whether the initial potential for the decay trace is set in the passive region or in the trans-passive region. This phenomenon is not observed in the iron-chromium alloys. 